\title{
Investigating the factors and methods of suicide in Ilam province (from 2012 to 2016)
}

\author{
Saeid Ahmadi ${ }^{1}$, Akbar Varvaei ${ }^{1 *}$, Ghobad Kazemi ${ }^{1}$
}

1. Department of Criminal Law and Criminology, Kermanshah Branch, Islamic Azad University, Kermanshah, Iran

*Corresponding author:Tel: +98 9183427497 Fax: +98

Address: Department of Criminal Law and Criminology, Kermanshah Branch, Islamic Azad University, Kermanshah, Iran

E-mail: dr.akbarvarvaei@yahoo.com

Received; 2017/08/18 revised; 2018/02/3 accepted; 2018/04/17

\section{Abstract}

Introduction: The phenomenon of suicide has been considered by experts of social sciences and psychology. Considering the issue of suicide, a precise analysis must first be carried out in a specific geographic region. Secondly, the cultural coordinates of the climate should be taken into account. The purpose of this study was to investigate the factors and methods of suicide in Ilam province.

Materials and methods: The statistical population of this research included all suicide cases committed in Ilam province from 2012 to 2016. The total sample size based on the recorded cases from 2012 to 2016 was 3078 cases. Data analysis of this research was done at two levels of descriptive and responding to research questions. At the descriptive level, indicators such as frequency, percentage, cross-tables, and frequency distribution charts were used. In the answer section of the research Kruskal Wallis and Xi-Du were used.

Results: There was a significant difference between the frequency of successful and unsuccessful suicides. $10.92 \%$ of suicides were successful and $89.08 \%$ were unsuccessful. Men tended to suicide more than women, but this was not statistically significant. In some age groups, suicide rates were higher than other groups, $34.7 \%$ were suicidal in the 21 to 25 age group, $30.06 \%$ in the age group of 31 and older, and $34.24 \%$ in the remaining age groups. Considering the methods, $73 \%$ of suicides have used pills over the last five years, and there was a significant relationship between the motivation of individuals and their tendency towards suicide $(48.4 \%)$.

Conclusion: The results of this study revealed that in committing suicide the individual, social, and psychological factors play the main roles, the results also presented the rate of being successful or unsuccessful in committing suicides, the gender of these attempters, their age range, the education level, the manner of committing, and finally their motive to commit suicide in years of 2012 to 2016.

Keywords: Suicide, Ilam province, Causes of suicide, Suicide practices

\section{Introduction}

The term suicide means an action on the part of an individual to put an end to his life consciously and arbitrarily, it was first used in 1737 and then it was accepted by the French Academy of Sciences in 1762.
The first systematic study of suicide was also introduced by Emile Durkheim in 1897 in a book called "suicide". In his book, he discusses the gap between religion and morality about suicide and as

Copyright (C) 2018 Journal of Basic Research in Medical Science. This is an open access article distributed under the terms of the Creative Commons Attribution 4.0 International License (https://creativecommons.org/licenses/by-nc/4.0/) which permits copy and redistribute the material, in any medium or format, provided the original work is properly cited. 
a result of suicide as a natural consequence of the relationship between the individual and the community (1).

Several studies have been carried out on the phenomenon of suicide in different parts of the country. These studies have tried to study the factors affecting this phenomenon from different perspectives in different periods of time.Ghanbari (2011) introduced the causes of suicide as family disputes, mental and physical illnesses, poverty and debt, and failure in life (2). Mousanejad et al. investigated different suicide attempters cases trying to describe the risk factors for committing suicide (3). In this regard, factors such as gender, age, occupation, poverty, addiction, disorders, psychological and family disputes were considered as risk factors for committing suicide. Other scholars such as Jamshidzadeh (2004), Ghaedi and his coalleagues (2006), and Eslaminasab (1992) have tried to find out about the causes and factors influencing suicide in another case study (4-6). But due to the constant change in the face of social problems that commit suicide and given the different types of motivation to do this in different parts of the country, the researchers and officials are required to design and execute research projects and try to design and implement appropriate prevention programs after they have become more aware of this social problem. Ilam province is one of the deprived and undeveloped provinces of the country. The depth of deprivation has a number of dimensions: economic, cultural, social, political, and so on. In many social injuries, such as girls' escape from home, addiction, and suicide the province rank is high on the table of social injuries among the provinces of the country (7). In general, multiple researches suggest a strong relationship between deprivation and social harm (8-12).

As Table 1 shows, there are some ups and downs in the rate of suicide in recent years, but it shows that this social problem still exists among the individuals. It should be noted that information about the rate of suicide and its reasons are classified in the provinces. Considering the researcher responsibility in Ilam province he decided to study the issue of suicide in Ilam province during the years of 2012-2016.

This paper seeks to identify the factors affecting suicide in order to provide solutions to the problem of how to prevent the growth of this social issue and reduce the number of suicides. Therefore, this research seeks to answer the main question that is what factors affect suicide in the province of Ilam?

\section{Materials and methods}

In this study, documentary method has been used to collect the data. In general, records of suicide cases are kept in certain places and personalized suicidal data are recorded. Part of the most basic features and useful information is to record the factors affecting suicide in these cases.

Statistical population: The statistical population of this research includes all suicide cases committed in Ilam province from 2012 to 2016. Unfortunately, there are no precise statistics on the number of suicides for various reasons. But in this research, we have tried to investigate all the information contained in the suicide cases in the years 2012 to 2016 . So the work is somehow all-encompassing.

Sample and sampling method: The total sample size in this study, based on the recorded suicide rate between 2012 and 2016, is 3078 cases. Of course, the present study does not claim that all of the successful and unsuccessful suicides that occurred during these five years have been investigated because, as stated above, all suicides cases during these years have not necessarily been officially registered.

Data collection procedure: This study is a documentary study in a way that it collects research data using the library method, as well as by referring to related centers and direct suicide cases. The Persian and Latin sources, translated books and journals texts, and finally articles 
related to the subject matter of the research were used. In the next step, the sources and sources of the research and the gathered information are categorized and used. The information obtained from the relevant files is analyzed and the research items are extracted, and as a result, by collecting all information from all records, the analysis of research data begins.

\section{Statistical analysis}

Data analysis of this research was carried out at descriptive and inferential levels. At the descriptive level, indicators such as abundance, percentage, cross-tables and frequency distribution charts were used. In the inferential statistics section, for comparing the means, Kruskal Wallis and Chi-square were used.

\section{Results}

In this section, the frequency and percentage of the research variables were used to describe the variables of the research. At first, the information obtained from the suicide rates was prepared in separate tables. The following table (Table 1 ), is describing the rate of being successful or unsuccessful in committing suicides; the gender of these attempters, their age range, the education level, the manner of committing and finally their motive to commit suicide in years of 2012 to 2016 are presented. Given that the variables presented in the present study are at the level of nominal and sequential measurement, both Chi-square and Kruskal-Wallis tests have been used. Both of these tests are nonparametric tests and for variables such as success and failure, gender, way of committing and motivating the Chi-square test and for the two variables of education and age, the Kruskal-Wallis test was used.

The findings show that there is a significant difference between the frequency of successful and unsuccessful suicides, in the last five years in the province of Ilam, $10.92 \%$ of suicides were successful and $89.08 \%$ were unsuccessful. Considering gender, it can be stated with 95 percent confidence that there is no significant difference between sex and suicidal tendency which means that the rate of suicidal tendency of men is approximately equal to the rate of suicidal tendency of women. It is also found that in the last five years, $47.46 \%$ of female and $52.54 \%$ of male were the suicide attempters. And about the age, the rate of suicide is different in different age groups and this difference is statistically significant which means that in some age groups suicide rates are higher than other groups, $34.7 \%$ of suicides were in the age group of 21 to 25 years, $30.06 \%$ in the age group of 31 and older, and $34.24 \%$ in the remaining age groups. Regarding the method of committing, it can be said that $73 \%$ of suicide cases used pills over the last five years, and $25 \%$ used selfimmolation, hookah, and so on. And finally considering the motive for committing suicide, there is a significant relationship between the motivation of individuals and their tendency towards suicide. In the descriptive part of the data, it was clear that in the past five years in the province of Ilam $48.4 \%$ were motivated by mental and psychological problems, $28.18 \%$ were motivated by family problems, $23.82 \%$ by unclear motives and $1.86 \%$ to suicide attempts were motivated by economic issues.

\section{Discussion}

Success and failure to commit suicide alone cannot give an accurate analysis of the causes of suicidal tendencies, but the usefulness of this information lies in the fact that researchers, experts, and others can refer to these statistics to see the attitudes of the community towards suicide. As shown, the rate of suicidal tendency in Ilam province has increased dramatically over the past years, with the total number of suicides almost double over the past five years, which is a very worrisome figure. 
Table 1. Description of the research variables.

\begin{tabular}{|c|c|c|c|c|c|c|}
\hline & \multicolumn{6}{|c|}{ Year } \\
\hline \multirow[b]{2}{*}{ Variable } & & 2012 & 2013 & 2014 & 2015 & 2016 \\
\hline & & $\begin{array}{c}\text { Frequency } \\
(\%)\end{array}$ & $\begin{array}{c}\text { Frequency } \\
(\%)\end{array}$ & $\begin{array}{c}\text { Frequency } \\
(\%)\end{array}$ & $\begin{array}{c}\text { Frequency } \\
(\%)\end{array}$ & $\begin{array}{c}\text { Frequency } \\
(\%)\end{array}$ \\
\hline \multirow[t]{2}{*}{ Success/Failure } & Successful & $69(15.6)$ & $50(13)$ & $74(10)$ & $54(9)$ & $61(7)$ \\
\hline & Failure & 371(84.4) & $329(87)$ & $690(90)$ & 553(91) & $823(93)$ \\
\hline \multirow[t]{2}{*}{ Gender } & Female & $213(48.4)$ & 174(46) & $370(48.4)$ & $290(47.7)$ & $414(46.8)$ \\
\hline & Male & $227(51.6)$ & 205(54) & $394(51.6)$ & $317(52.3)$ & $470(53.2)$ \\
\hline \multirow[t]{5}{*}{ Age (year) } & $<15$ & $2(1)$ & $9(2)$ & $20(26)$ & $8(1.3)$ & 17(2) \\
\hline & 16 to 20 & $95(21)$ & $84(22)$ & $124(16.2)$ & $93(15.3)$ & 68(7.6) \\
\hline & 21 to 25 & $169(38)$ & $108(29)$ & $216(28.2)$ & 229(37.7) & $359(40.6)$ \\
\hline & 26 to 30 & $44(10)$ & $55(15)$ & 101(13.2) & 107(17.6) & $260(29.4)$ \\
\hline & $>30$ & $130(30)$ & $123(32)$ & $303(39.8)$ & $170(28.1)$ & $180(20.4)$ \\
\hline \multirow[t]{2}{*}{ Education } & Illiterate & $426(97)$ & $350(92)$ & 721(94) & $559(98)$ & 853(96) \\
\hline & Literate & $14(3)$ & $29(8)$ & $43(6)$ & $8(2)$ & $31(4)$ \\
\hline \multirow{5}{*}{$\begin{array}{l}\text { Way of } \\
\text { committing }\end{array}$} & Pill & $304(69)$ & $228(76)$ & $599(78.4)$ & $388(64)$ & $686(77.6)$ \\
\hline & Arms & 16(3.6) & $13(3.4)$ & $16(2)$ & $35(5.7)$ & $13(1.4)$ \\
\hline & Self-immolation & $40(9)$ & $20(5.2)$ & $29(3.7)$ & $52(8.5)$ & $21(2.3)$ \\
\hline & Hanging & $50(11.3)$ & $27(7.12)$ & $56(7.3)$ & $37(6)$ & $52(5.8)$ \\
\hline & Others & $30(7.1)$ & $31(8.28)$ & $64(8.6)$ & $95(15.8)$ & $112(12.9)$ \\
\hline \multirow{4}{*}{$\begin{array}{l}\text { Motive for } \\
\text { committing }\end{array}$} & Family & $129(29.3)$ & $94(24.8)$ & $214(28)$ & $180(29.6)$ & $259(29.2)$ \\
\hline & Mental & $199(45.2)$ & $182(48)$ & $360(47.1)$ & $281(46.2)$ & $391(44.2)$ \\
\hline & Economic & $5(1.1)$ & $7(1.8)$ & $6(1)$ & $26(4.2)$ & $11(1.2)$ \\
\hline & Unknown & $107(24.4)$ & $96(25.4)$ & 184(23.9) & $120(20)$ & $223(25.4)$ \\
\hline Total & & $440(100)$ & $379(100)$ & 764(100) & $607(100)$ & $884(100)$ \\
\hline
\end{tabular}

Considering gender as one of the variables mentioned in this study, the results show that over the past five years, the rate of male's tendency towards suicide has increased compared to females. Studying age groups over the past five years, suicide tendency in the age group of 21 to 25 has been observed more frequently in Ilam province, and only in the years 2013 and 2014 the incidence of tendency in the age group of 31 and above is more than the other three years. There is a significant difference considering the educational variable on the tendency of literate and illiterate people to commit suicide. Therefore, it seems that decreasing the level of suicide could be achieved by improving education and providing appropriate educational conditions. 
Table 2. The results of inferential statistics associated with testing the present research hypotheses.

\begin{tabular}{llclccc}
\hline Variable & & Percent & Test & Statistic & P value & Result \\
\hline Success/Failure & Successful & 10.92 & Chi-square & 26.33 & 0.001 & Approved \\
Gender & Failure & 89.08 & & & & \\
Age (year) & Female & 47.46 & Chi-square & 6.26 & 0.515 & Rejected \\
& Male & 52.54 & & & & \\
& $<15$ & 1.78 & Kruskal-Wallis & 21.29 & 0.001 & Approved \\
& 16 to 20 & 16.42 & & & & \\
Education & 21 to 25 & 34.7 & & & & \\
Way of Committing & 26 to 30 & 17.04 & & & & \\
& $>30$ & 30.06 & & & & \\
& Illiterate & 95.4 & Kruskal-Wallis & 35.39 & 0.001 & Approved \\
& Literate & 4.6 & & & & \\
& Pill & 73 & Chi-square & 33.25 & 0.001 & Approved \\
& Gun & 3.22 & & & & \\
Motive for Committing & Self-immolation & 5.74 & & & & \\
& Hanging & 7.504 & & & & \\
& Others & 10.536 & & & & \\
& Family & 28.18 & Chi-square & 29.52 & 0.001 & Approved \\
& Mental & 46.14 & & & & \\
\hline & Economic & 1.86 & & & & \\
\hline
\end{tabular}

The method of committing is one of the variables that can be an effective measure in preventing suicide in Ilam province by accurate identification of its dimensions. In all of the years under investigation, suicide attempted with conventional pills has been used, so that nearly $73 \%$ of suicides in the past five years have been done in this way. It seems that the availability of this tool and its ease of use have a great influence on the tendency to use this method. Another point is that suicide attempters seem to think that death with this tool is calm and more relaxed compared with the more painful methods of guns, selfimmolation and throats. Considering the motive of committing, it can be stated that psychological causes are ranked as first and family issues as second. The factors that cause mental and psychological problems can be found in collective unemployment -even among educated people-, religious beliefs, marital conflicts, family life, mental illness, failure in love and personality disorders, poverty, addiction, and unfavorable economic conditions, urban living conditionsespecially in industrialized cities-, and the disintegration to social groups. What is important is the role of support of family members, especially parents, in preventing the occurrence of these suicides. It seems that if the family play a constructive and positive educational role we will not see the double rate of suicide in this province. With the growth and the development of societies and the movement towards modern society, family members interact less and are less concerned with the needs of family members, so the individuals are thrown into a tense world of highly harmful modernity. Today, in Ilam province, this problem has taken place. This deficiency can be resolved with the help of supportive institutions for the proper socialization of the people, child care centers, schools, universities, and even the media which can play an important role. The findings of the present study are in line with some studies including: Ghasempour, Spleman, Raeis, Mousavi and Gasan (12-15,). Durkheim attributed the rise of suicide in the nineteenth century to the process of modernism and the factors such as the emergence of individualism, urbanization, industrialization and the absence of religious authority which reflects the decline of social unity (1). But in modern research, there is no relationship between 
modernity and suicide. Meanwhile, suicide rates have increased in some societies, but declined in other countries and even reached zero, acceptance of social commitment with accountability and access to education is one of the explanations for this.

\section{Conclusion}

The results of this study revealed that in committing suicide the individual, social, and psychological factors play the main roles, the findings show that there is a significant difference between the frequency of successful and unsuccessful suicides. Considering gender, the findings showed no significant difference between sex and suicidal tendency. About the age, the rate of suicide is different in different age groups and this difference is statistically significant which means that in some age groups suicide rates are higher

\section{References}

1. Durkheim, E. Suicide. A study in sociology. Glencoe, Illinois: The Free Press. 1951. P. 405.

2. Janghorbani M, Sharifirad G. Completed and attempted suicide in Ilam, Iran (1995-2002): incidence and associated factors. Arch Iranian Med 2005; 8 (2): 119-26.

3. Suhrabi Z, Delpisheh A, Taghinejad H. Tragedy of women's selfimmolation in Iran and developing communities: a review. Int J Burns Trauma. 2012; 2(2):93-104.

4. Azizpour Y, Asadollahi K, Sayehmiri K, Kaikhavani S, Abangah G. Epidemiological survey of intentional poisoning suicide during 1993-2013 in Ilam Province, Iran. BMC Public Health. 2016; 16:902. doi: 10.1186/s12889-016-3585-9.

5. Azizpour Y, Sayehmiri K, Asadollahi $\mathrm{K}$, Kaikhavani S, Bagheri $\mathrm{M}$. Epidemiological study of suicide by physical methods between 1993 and than other groups, regarding the method of committing, it can be said most of suicide bombers used pills. And finally considering the motive for committing suicide, half of attempters were motivated by mental and psychological problems, and then family problems, unclear motives, and economical issues.

\section{Acknowledgment}

This study is written based on the results of a Ph.D dissertation entitled "Developing a comprehensive pattern to prevent suicide among women in the city of Ilam with code No. 192208059520111.

\section{Conflict of interests}

There is no conflict of interest.

2013 in Ilam province, Iran. BMC Psychiatry. 2017; 17(1):304. doi: 10.1186/s12888-017-1461-5.

6. Carretta CM, Burgess AW, Welner M. Gaps in Crisis Mental Health: Suicide and Homicide-Suicide. Arch Psychiatr Nurs. 2015; 29(5):339-45. doi: 10.1016/j.apnu.2015.06.002.

7. Azami M, Darvishi Z, Sayehmiri K. Systematic review and meta-analysis of the prevalence of anemia among pregnant Iranian women (2005 2015). Shiraz E-Med J. 2016; 17(45):e38462. doi: 10.17795/semj38462.

8. Daddoust L, Khankeh H, Ebadi A, Sahaf R, Nakhaei M, Asgary A. The Vulnerability of the Iranian Elderly in Disasters: Qualitative Content Analysis. Iran J Nurs Midwifery Res. 2018; 23(5):402-408. doi: 10.4103/ijnmr.IJNMR_127_17.

9. 9. Brandon C. Welsh and David P. Farrington. Crime Prevention and Public Policy. Oxford Handbooks. 
2001.

doi:

10.1093/oxfordhb/9780195398823.01 3.0001 .

10. Carrington, K., Hogg, R., Scott, J., Sozzo, M. The Palgrave Handbook of Criminology and the Global South. Palgrave Macmillan. 2018. doi:10.1007/978-3-319-65021-0.

11. Najafi A. [The neo-criminology: The new studies of Criminological sciences (the articles collection)]. Mizan Publication, Tehran, Bahar. 2009. (In Persian)

12. Charernboon T, Patumanond J. Social Cognition in Schizophrenia. Ment Illn. 2017; 9(1):7054. doi: 10.4081/mi.2017.7054.
13. Spleman, W. Beyond bean-counting: New approaches for managing crime data. Washington, DC: Police Executive Research Forum. 2008.

14. Bazrafshan MR, Sharif F, Molazem Z, Mani A. Exploring the risk factors contributing to suicide attempt among adolescents: A qualitative study. Iran J Nurs Midwifery Res. 2016; 21(1):93-9. doi: 10.4103/17359066.174747.

15. Gasan R. The applied criminology (translated by: M. Keynia). Tehran, Motarjem Publication, $1^{\text {st }}$ Publication. 1991: P.95. 